Report on the Workshop on Barriers to the Application of Forestry Research Results

C.T.S. Nair, T. Enters and B.Payne
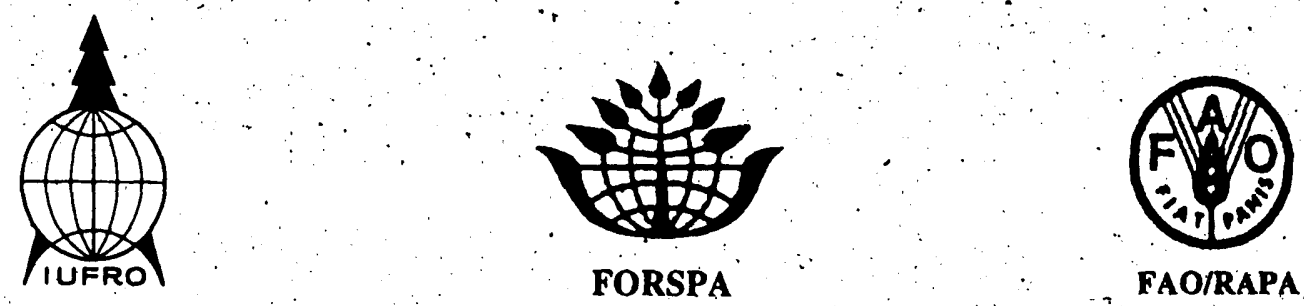

FAORAPA.

CENTER FOR INTERNATIONAL FORESTRY RESEARCH office address: Jalan Gunung Batu 5 Bogor 16001 Indonesia mailing address: P.O. Box 6596 , JKPWB Jakarta 10065 Indionesia tel.: +62 (251) 34-3652 fax: +62 (251) 32-6433

e-mail: cifor @cgnet:com 


\section{CIFOR}

CIFOR was established under the CGIAR system in response to global concerns about the social, environmental and economic consequences of loss and degradation of forests. It operates through a series of highly decentralized partnerships with key institutions and/or individuals throughout the developing and industrialized worlds. The nature and duration of these partnerships are determined by the specific research problems being addressed. This research agenda is under constant review and is subject to change as the partners recognize new opportunities and problems.

\section{IUFRO}

The International Union of Forestry Research Organizations (IUFRO) founded its Special Programme for Developing Countries (SPDC) in 1983 to provide assistance to developing and economically disadvantaged country institutions and scientists to strengthen their forestry research capability. With support from various donors, the IUFRO SPDC has organized regional research planning workshops, and it has produced self-learning courses in research planning and management and in basic forestry statistics (in English, French, and Spanish). It provides travel grants to allow deserving younger researchers to participate in scientific meetings, and it distributes a quarterly Information Bulletin for Developing Countries which contains abstracts of forestry research publications selected for their value primarily to tropical forestry researchers. The SPDC fosters inter-institute collaboration, and it cooperates actively with other organizations having complementary aims.

\section{FORSPA}

The Forestry Research Support Programme for Asia and the Pacific (FORSPA) is designed to enhance country capacity in forestry research through facilitating networking and twinning, transferring technology, especially through TCDC arrangements and augmenting human resource capacities through improved access to information. It provides technical and financial support for adaptive field research on priority problems relevant to developing countries in the Region. Funded by the Asian Development Bank and the United Nations Development Programme,FORSPA is implemented by the Food and Agriculture Organization of the United Nations.

\section{FAO/RAPA}

The FAO Regional Office for Asia and the Pacific monitors major developments and trends in food and Agriculture (including forestry and fisheries), promotes technical cooperation among countries of the region, maintains liaison with regional organizations, supports FAO Country Representatives in the region, participates in regional and inter-country projects, and provides technical assistance and advice to the 30 FAO member countries in the Asia-Pacific region. 


\section{Foreword}

Most of us who have been involved in forestry research and research management have been feeling a little uneasy about the ultimate outcome of research efforts. While the outputs continue to be very low in comparison with the needs, an important problem has been the poor application. Are we addressing the right kind of problems or is it because we have failed to effectively market our research? No doubt research is intellectually stimulating and rewarding, but it seems that very little attention has hitherto been paid to issues concerning their field application. Consequently the status of forestry research continues to be low and policy makers and planners assign a low priority to research. While researchers often tend to blame others, it is time for some serious introspection and critical review of what we have done or what we are doing. Is our research relevant and target oriented? Are we developing innovations that will substantially alter and improve the pattern of natural resources use? It is important that these questions are effectively addressed, to prevent the further slide of forestry research to inconsequence.

Another basic question that needs to be asked is the productivity of research itself. We cannot talk of effective application of research results if research results are low and of poor quality. Therefore research itself must be enhanced in quantity and quality, and in all fields of forestry.

It is hence timely that IUFRO, FORSPA, CIFOR and FAO-RAPA have joined hands to address the problem, and the outcome of this is the Workshop on the Barriers to the Application of Forestry Research Results held at Bangkok during 24 to 28 October 1994 While tangible solutions are still far away, the Workshop brought together different interest groups and facilitated a frank discussion on some of the problems. There was a clear recognition of the existence of barriers, their origin and nature and the urgency to overcome them. It is important that the findings are widely disseminated and shared to facilitate follow up action at different levels. I do hope that these proceedings will generate further interest and help to pursue appropriate action. The challenges of forestry research are tremendous and so are the opportunities. It remains for us all to collectively address the challenges and harness the opportunities.

M.N. Salleh

President, IUFRO 


\section{CONTENTS}

Introduction 1

Background 1

Objectives 2

Organization 2

Barriers: are they real? $\quad 2$

Causes of barriers 3

Identification of researchable problems 3

The research process $\quad 5$

Communication and Extension $\quad 7$

$\begin{array}{ll}\text { Problems at the application stage } & 7\end{array}$

Response to the Problems: Case studies $\quad 8$

Where do we go? $\quad 8$

Concluding remarks 9

Some qualifying observations 9

Acknowledgements 10

Appendix 1 - List of Papers and Abstracts 11

Appendix 2 - List of Participants 30 


\title{
Report on the Workshop on Barriers to the Application of Forestry Research Results
}

\author{
C.T.S. Nair ${ }^{1}$, T. Enters ${ }^{2}$ and B. Payne
}

\begin{abstract}
Summary
Despite the increase in forestry research investment, the scientific base of forestry field practices remain weak, primarily due to the barriers to the application of research results. While barriers become visible at the application stage, their origin could be traced to all the preceding stages, including problem identification, research process and communication and extension. Mechanisms for identification of researchable problems, especially through the involvement of users are at best weak. The problem is further aggravated due to compartmentalized research, failure to incorporate local technical know-how and weaknesses in research management including inappropriate evaluation systems. A substantial proportion of research results are not communicated to potential users, but directed at other researchers. Even when relevant results are made available, they may remain unutilized as potential adopters may have objectives not taken into account while designing research. Also forestry services geared to enhance revenue in the short term may fail to take cognizance of the long term benefits from the adoption of improved practices.
\end{abstract}

\section{Introduction}

\section{Background}

Over the last decade there has been a substantial increase in investment in forestry and agroforestry research. The FAO Directory on Forestry Research Institutions, published in 1993, lists more than 140 institutions involved in forestry research in the Asia-Pacific Region. This in no way is an exhaustive and up-to-date list and does not include all institutions with forestry research capabilities. The International Union of Forestry Research Organisations (IUFRO) counts approximately 15,000 research scientists employed by its member institutes. There have been significant international efforts in support of forestry research, like the establishment of the (ICRAF), the International Union of Forestry Research Organisations Special Programme for Developing Countries (SPDC), and the Center for International Forestry Research (CIFOR). Regional programs have been initiated, like the Forestry Research Support Programme for Asia and the Pacific (FORSPA), Forests Tree Improvement Project (FORTIP), Forestry/ International Centre for Research in Agroforestry

Fuelwood Research and Development Project (F/FRED), Asia-Pacific Agroforestry Network (APAN) and ASEAN Forest Tree Seed Centre (AFTSC). In addition; research support has been provided through various donor-funded activities. Although investment in forestry research remains low in comparison with agriculture, outlays have increased, leading to the establishment of new facilities and an increase in the number of personnel involved in forestry research. This is reflected in the growing number of journals and papers dealing with different aspects of forestry and agroforestry. Expanded involvement of nongovernmental organisations and the private sector in forestry research is another noteworthy development.

One major issue that has to be considered in augmenting research capabilities, is how effective the research output has been or will be in addressing key problems concerning conservation and management of forest and tree resources. In other words, are research results being applied in the field, and/or are research efforts relevant to the problems which have been identified? Contrary indications exist showing the prevalence of barriers to the application of research results. While the textbook paradigm of research,

1 Forestry Research Support Program for Asia and the Pacific, FAO Regional Office for Asia and Pacific, Maliwan Mansion, Phra Atit Road, Bangkok 10200, Thailand.

2 Centerfor International Forestry Research, P.O. Box 6596 JKPWB, Jakarta 10065, Indonesia

3 International Union of Forestry Research Organizations, IUFRO Secretariat, Seckendorf-Gudent- Weg 8, A-1131 Vienna. Austria. 
extension and application is a straightforward model, the reality may be far removed from our common assumptions.Increased research efforts, it would seem, have not percolated to the field, and what is practised has not yet undergone perceptible changes. Plantation techniques and silvicultural systems have continued to be traditional. The expertise on tree breeding for enhanced productivity has not been widely applied. Pest problems continue to undermine productivity, and some pest problems have persisted for decades. Management of natural forests has not made any significant improvements. Extensive logged-over areas have been severely degraded. Regeneration is a chance outcome dependent on a combination of favourable environmental and socio economic conditions; it is not based on intervention through proven technologies. While agroforestry and community forestry have received increased attention over the last two decades, it appears that we still do not know enough to be able to say "what can make a difference".

While some problems are outside the domain of conventional forestry research, there seems to be a clear recognition that barriers to the application of forestry research results do exist. Hence it becomes imperative to consider the circumstances under which forestry research has brought about significant improvements in management practices and policies, and, conversely, when it has produced nothing more than publications with little effect on resource management.

\section{Objectives}

Understanding the nature of the barriers to the application of research and developing a strategy to overcome them are prerequisites for appropriate, problem-oriented and cost-effective research. To facilitate a clear understanding of the issues and to identify measures to overcome the problems, IUFRO, FORSPA, CIFOR and FAO/RAPA jointly organised the Workshop on Barriers to the Application of Forestry Research Results, 24 -28 October 1994, in Bangkok. The workshop had the following objectives:

- to identify and analyse the different kinds of barriers that affect the research process and the application of research results in forestry;

- to assess the current strategies for identifying research prioritie $\mathrm{s}$ and to evaluate the usefulness and appropriateness of research;

- to develop a strategy framework for overcoming the barriers at different levels.

\section{Organization}

Forty-seven participants from twenty countries and eight international organisations attended the workshop. Participants were selected to represent various groups-researchers, research managers, forest managers, extension agents, NGOs, advocacy groups, industries and donor agencies to reflect the diversity of perceptions (See Appendix 2 for a list of participants). Opening addresses by Dr. M.N. Salleh, President of the International Union for Forestry Research Organisation (IUFRO) and Mr. Obaidullah Khan, Asst. Director General and Regional Representative FAO/RAP A provided the backdrop to the discussions. Salleh emphasised the need for teamwork and improved communication amongst researchers and with end users, to take advantage of windows of opportunity. Khan's presentation focused on how science and technology should empower rural communities, and the need for improving traditional practices to the benefit of the poor and disadvantaged.

An introductory session set the scene for the workshop by questioning the conventional paradigms of research, extension and application. Presentations by two young scientists from China and Vietnam (who were invited to attend the workshop on the basis of an essay competition conducted by FORSPA) helped to focus on the workshop's objectives. Subsequent sessions were organised in such a way that representatives of each of the interest groups were able to present their views through invited presentations by two or three lead speakers, followed by discussions (See Appendix 1 for a list of papers presented). Although lead speakers had been provided with a questionnaire to guide the preparation of their papers, this proved to be ineffective. Instead, a wide range of cross-cutting issues was brought out, some of which were not necessarily related to the workshop' s objectives. Case studies from New Zealand, Australia and Malaysia provided insights into responses to deficiencies in research systems and to reductions in funding. Discussion group meetings and a concluding plenary session helped crystallise the issues.

\section{Barriers: are they real?}

It was generally agreed that the proportion of research results actually adopted and put into practice is very low. Even for a country like China, with a strong emphasis on practical 
application, it was noted that less than 30 per cent of research results are actually used (Wang Hong). Throughout the region, a widening chasm between research and practice is evident from the limited reliance on research institutions by farmers and foresters. They continue to adopt and adapt practices based on their own experiences rather than on what researchers propose. Cases of nonadoption are more prevalent than successful applications (especially in tree growing). Instances of successful introduction of species like eucalypts, acacias and poplars facilitate through research do exist but, for most other species, and particularly indigenous species, the state of technical know-how at the field level has not improved substantially. Research findings, even when they are relevant, have remained in the confines of research institutions and their field stations.

To investigate the nature of the barriers to the adoption of forestry research results, a closer look at the situation in the agricultural sector has been advocated. No doubt, there are some similarities, but also significant differences. Although local communities have played an important role in managing forest and tree resources for many centuries, the history of forest management has been shaped by public-sector control, largely aimed at enhancing industrial wood supply and augmenting government revenue. As a result, forestry research is narrowly focused and often isolated from the socio-cultural and economic realities. The multi-functionality of forestry and the complexities of resolving conflicting objectives complicate research in forestry, compared with that in agriculture. Tree planting by farmers and communities has continued, even if constrained by adverse policy conditions. However, it is largely based on traditional knowledge developed through on-farm experience. Recent emphasis on community and private-sector participation in forestry has led to widening the range of clientele for forestry research, which brings the issue of barriers to its application even more to the forefront.

\section{Causes of barriers}

Traditionally, a $\mathrm{n}$ effective communication mechanism or extension recipe backed up by "appropriate incentive packages" was considered sufficient for successfully disseminating research results.This assumed that the innovations developed and tested by researchers would solve an identified problem if only the users received necessary technical and other support. However, such a simple, one-way approach is inadequate to explain barriers to research use. Most participants agreed that some barriers originate at the very early stages of research. These may become aggravated in subsequent phases of the entire research-application continuum, and additional barriers may arise at any point. This continuum can be portrayed as follows:

(i) the identification of researchable problems, the very objective of undertaking research;

(ii) the research process itself;

(iii) the communication of research results, particularly in extension;

(iv) the adoption of research results.

\section{Identification of researchable problems}

Researchers normally assume that their problem selection is appropriate and their problem definition is accurate, but this is not often the case. Researchers and their clients, the potential users of research, may have quite different perceptions of what problems are important and should be addressed. Research on the wrong problems is irrelevant. And if problems chosen for research are not correctly defined, the knowledge derived from their solution is unusable.

Why do researchers choose the wrong problems? That is, why do perceptions of relevant problems differ between researchers and users? The answer lies partly with the way forestry organisations and forestry research have evolved historically and the training that is provided to forestry researchers.

- traditionally, most forestry research has focused on maximising wood yield from managed forests, forests from which people have been excluded.

Research has focused on forests managed by public agencies, forests where issues of land and tree ownership and tenure have not been important considerations.

- Research has focused ontrees their growth and dynamics, pests and diseases, utilisation, etc.

- Much forestry research has attempted to emulate the green revolution strategy in agriculture, to maximise yield from introduced, fast-growing species.

- The traditional skill repertoire of forestry researchers has made them ineffective in dealing with people-centred issues. Research 
designs, techniques and skills associated with conventional forestry are inappropriate for community forestry, agroforestry and private small-scale forestry.

Appropriate problem identification to make research more demand-driven was therefore considered a critical first step in preventing the emergence of barriers . Existing mechanisms for identification of problems were conceded to be weak, at best. Interests of researchers, rather than the needs of prospective clients/users of research results, are the main driving forces for most research. Policy stipulations for setting a more demand-driven research agenda are not available or, when available, they are too vague to provide meaningful direction for research prioritisation. In fact, when they set out to identify researchable problems, researchers too often are faced with policy guidelines based on questionable assumptions. Instances where researchers are compelled to undertake research on problems that they know are irrelevant and contrary to facts are not rare (Hafild). The tendency to set research agendas which draw upon untested information was criticised by Enters. He used the example of the "eco-crisis theory" to argue that information of only limited scientific value is nevertheless appealing to researchers, donor agencies and the development community because it can be used to define problems that suit their interests and their preconceived solutions.

For defining research priorities and setting research agendas, mechanisms like Advisory Committees and Research Councils do exist in several countries, but their effectiveness varies greatly. National-level committees usually coordinat ethe activities of different agencies and try to avoid duplication of efforts. The composition of these committees is often restricted to researchers and research managers. Policy makers, planners and other prospective users (especially representatives from forestry departments) are usually under-represented. Other than considering the broad issues, no serious efforts are made to indicate research priorities and directions. Where such efforts are attempted, decisions are frequently based on preconceived notions or, what Enters, called, myth or misinformation. Farmers, foresters and industry representatives, who face day-to-day problems and who should be the primary customers of forestry research results, are seldom represented in the decision-making institutions. While it is realised that research committees have an important role to play and have succeeded in reducing research duplication to some extent, the ultimate aim of replacing supply-driven research with a demand-driven system is still a long way off.

Thus, forestry research programs are drawn up with little consultation (Gunasena), with decisions on research topics made by researchers themselves (Joshi), according to their interests (Wanida ) and personal backgrounds (Bahuguna). The selection of research problems often is based on (i) what will satisfy policy makers and/or immediate superiors and (ii) what will advance the career of those undertaking research. The choice of research topic may be influenced by the head of the research organisation (Bahuguna). Rules and regulations set by governments often stifle the search for innovative ideas through scientific pursuits (Wong). Funding arrangements generally confirm biases against conducting applied and adaptable research and towards the elegant and publishable. Success in a research career is not achieved by making the tasks of the foresters or farmers easier. The "publish or perish" approach forms an important driving force of present-day research. The result of all this too often is research results which are complicated and impractical, while users require only simple and applicable improvements (Dzung).

While some of the forces that influence research direction are beyond the control of researchers, participants indicated that many researchers may actually prefer to live within a "publish or perish" culture. This frees them from having to seek active collaboration with research partners and customers. That some researchers fail to make use of indigenous knowledge and view experiments conducted by farmers or foresters as "unscientific", is also very disturbing. This often stems from a paternalistic attitude towards rural communities (Katerere), which implicitly assumes that local people are the very cause of the problem.

A tendency to copy from approaches found suitable in different socio-economic and environmental contexts is another key factor undermining the relevance of research. Sociocultural and economic issues confronting the rural and informal sector are frequently ignored (Katerere). As Chun Lai pointed out, overcoming the barriers to the application of agroforestry research results is a daunting challenge that requires going beyond forestry and into the agricultural and social science domains. It also requires recognition of the importance of formerly under-explored issues, such as practical research on marketing forestry and agroforestry products. 
With the tree-centred view which dominates most forestry research (Henderson), multi-disciplinary, holistic approaches receive only lip service.

Identification of problems has become more complex, especially in the context of the multiplicity of objectives of forest and tree resources management. Some objectives are mutually exclusive, and there are no mechanisms to determine the extent of trade-offs between conflicting objectives. Forest managers themselves have not resolved these conflicts, which provide weak signals to research. Quite often, prospective research clients who deal with day-to-day problems look for instant solutions, which are not available. Instead, solutions may require substantial basic, strategic and applied research. Such high and unrealistic expectations are also factors that contribute to the negative views on research. Consequently, researchers are criticised for not addressing the "pressing problems". However, many of these may not require research, but rather the willingness and ability to use existing and available information.

Although most participants joined in favouring a demand-driven forestry research model, it was also recognised that some very useful and innovative research is triggered by a researcher' s “bright idea". In addition, not all researchers are out of touch with, reality and the needs of users. While the current approaches for selecting research topics have all too often led to inappropriate, non-adaptable, or even harmful results, evidence of good work is not unknown.

\section{The research process}

While problem identification was considered as a critical element, the very process of undertaking research came in for scrutiny by several participants. The main problems identified were:

1. lack of holistic approach;

2. inability to incorporate local technical knowhow;

3. bureaucratic nature of research management;

4. inappropriate evaluation and reward system.

Lack of holistic approach. The reductionist approach of modern science, although sometimes necessary to provide an in-depth understanding, has resulted in compartmentalisation of research along disciplinary lines (Gurmit). Each discipline has developed its own repertoire of approaches, and mechanisms to integrate them are, at best, weak. Institutions with a long history are found to be more susceptible to such approaches, especially when research management has not striven to develop aviable problem-focused system. Divisions and units organised along disciplinary lines are most often compelled to perform within the disciplinary boundaries and are not encouraged to transgress into outside areas. Instances are common where similar, if not identical, field trials. are set up by researchers in different divisions to deal with the same problem. While the importance of inter-disciplinary research is acknowledged, the mechanisms and incentives for its support are very weak. Also, it was pointed out that researchers lack the orientation and skills to work in inter-disciplinary teams.

Inadequate consideration of social science issues is another factor which has accentuated the barriers . Current forestry research is primarily oriented towards the biologica/silvicultura1 aspects. In a situation where resource conflicts are not serious and enhancing productivity of wood is the only objective, such narrow orientation is justified. However, conflicting demands from the increasing numbers of forest users require broadening the research horizon. Social science research is still extremely weak in most forestry research institutions. Where it exists, the thrust is to (i) assess the economic viability of technical alternatives and (ii) to develop data bases on key aspects of production, consumption and trade of important products Linkages between forestry research institutions and social science institutions are not particularly strong. Lacking input from the social sciences, researchers fail to develop implementable technologies, management strategies or policies, and research remains patchy (Wanida). Where rules and regulations discourage researchers in different disciplines from collaborating, research designs tend to be faulty. This severely limits the integration of knowledge at the operational level.

Compartmentalisation, however, is not exclusively a problem of forestry research institutions. A number of structural barriers are due to organisational mandates and territoriality (Chun Lai) resulting in a restricted flow of information and unwillingness to cross institutional boundaries. Arbitrary grouping of administrative functions under different departments and ministries (as in the case of separate ministries and departments for agriculture and forestry) have further accentuated the barriers, especially in developing cross-disciplinary land uses like agroforestry. 
Incorporation of local technical know-how. Most research is initiated on the assumption of inadequacy, or even total lack, of local know-how. Farmers are regarded as helpless agents or even the cause of the problem. Their ability to experiment and to devise viable solutions to problems based on their understanding of local conditions and resource availability is discounted (Enters). Farmers seldom record their accomplishments in writing, present papers on their discoveries, or patent their inventions. Hence, informal research is not recognised. Instead, efforts are directed at transplanting technologies totally alien to the area, rather than building from what is already known to local communities. Hafild illustrated this point with the example of alang alang (Imperata cylindrica) reclamation efforts in Indonesia. Causes of the "alang alang problem" and the measures to deal with them are known to local communities, but formal research has seldom made an effort to build on this knowledge. Cultural barriers between local communities and researchers, and the tendencies to describe local practices as "backwards", "primitive", or "traditional" further aggravate the problem.

The significance of local know-how and farmer-initiated research seems to be more important in agroforestry and other rural land uses. The variety of crop combinations, including the use of several cultivars, and the multitude of cropping patterns and cultivation practices normally employed are an outcome of farm-level innovation and farmer-to-farmer extension, This situation is not limited to food crops alone. There are several instances where local communities have perfected the techniques of tree growing (Khan). Building on what is already known will lower the adoption barriers. As Chun Lai suggested, a useful exercise before initiating any research, is to assess

(i) what we know we know,

(ii) what we think we know, and

(iii) what we know we don't know

about specific technologies under on-farm conditions with inputs from farmers, extension agents and researchers.

Bureaucratic research management. A number of participants drew attention to the bureaucratic nature of research management that impairs creativity and original thinking. "Management has the responsibility of providing vision, leadership and anticipating the future direction of research. It must prioritise the research program and establish a reasonable balance between basic, strategic and applied research" (Katerere). However, experience points to the contrary. The "command and control mode of forestry research agencies" has adversely affected the integration of the concerns of stakeholders (Ganguli). Ineffective assessment of capacity and poor monitoring systems accentuate the problem of unfocused research. In many cases, research institutions have no critical mass of human resources. Still, efforts persist to spread resources over an even larger number of areas/topics, resulting in low productivity.

Some participants pointed out that forestry research is not able to attract motivated individuals. Funding constraints, lack of facilities and uncertain career prospects make research unattractive, and it becomes a dumping area for those who are indifferent. This may result in a vicious cycle of low motivation, low output and low investment. Often a major proportion of resources allocated for research are used for salaries and maintenance of the system, with a declining allocation of funds for actual field research.

Inflexible and bureaucratic research management were identified as other problems that hamper application-oriented research. Coupled with an unfavourable policy framework, research systems have not been able to deal with real issues relevant to those groups who need assistance, but whose pleas are unanswered.

Reward and accountability system. There was general agreement that the existing system for assessment of performance is unduly focused on publications. This compels researchers to increase the number of publications, rather than producing results that are of direct application value. Incentives and rewards for conducting applied field research in response to users' needs, particularly the needs of poor, remote rural land managers are few. On the contrary, reward systems favour those who conduct esoteric, hightech, publishable research, even if it is of questionable relevance. Institutional and funding arrangements generally confirm biases against useful, adaptable research, and towards the refined and publishable. Success in a research career is not attained by finding practical solutions to real problems or by making a manager's job easier. Participants were critical of the system which favours publications and exchange of information 
by peers, while far less importance is attached to demonstrating results to potential adopters, who are referred to as "beneficiaries" or "target groups" in research proposals. While participants realised that more demand-driven research is not a panacea for overcoming research deficiencies, it could directly influence the reward system and thus lead to a reduction in irrelevant undertakings.

\section{Communication and extension}

Poor communication between researchers and users is a major barrier to effective transfer and application of potentially useful research results which are not always user-friendly and quite often inaccessible. Many participants agreed that results are not effectively communicated to the users, but instead directed at other researchers. A concerted effort is needed to appreciate and understand the diverse clientele. This includes rural farmers who are not part of formal decision making and are not reached by technical and scientific publications (Katerere). Several papers discussed the mechanisms for communication of research results and their efficacy. However, the diversity of situations makes it unlikely that a blanket or pre-packaged communication/extension model will have universal applicability. The main issues discussed were; (i) who is responsible for extension; and (ii) what is the method of extension.

Responsibility for extension. The question of who should undertake extension received considerable attention. Differences in approaches and opinions reflect the variety of situations that exist in different countries. Some participants pointed out that researchers should allocate part of their time for extension purposes (Wong) and the reward system should reflect this (Wang Houran) Others pointed out that extension requires special skills and is better undertaken by those who are specifically qualified and trained for the purpose (Tewari). Participants agreed that with the diversification of the research clientele, extension will become more complex. Given the range of situations, no one approach will suit all situations. Each must be examined before assessing the appropriate extension mechanism and personnel, but where farmers are the research result users, a farmer is most probably the preferred extension worker (Viquez).

Extension method. While the merits and demerits of different extension methods were not discussed, there was agreement that the suitability of these is situation-specific and directly related to the social, economic and cultural status of the intended beneficiary groups. Participants did indicate some of the more general problems of extension. Traditional extension agencies often adopt a mechanistic approach, aimed at fulfilling targets fixed at official levels. For example, a number of transfers may be set for pre-packaged techniques for establishment of woodlots or community nurseries. The essence of extension, two-way communication, is completely ignored in fulfilling such targets. Dialogue and feedback from "beneficiaries" are neglected. Non-adoption of top-down directions is treated unsympathetically, and no efforts are made to assess the reasons for noncompliance. Rather than a "researcher-extension agent-user partnership", extension methods too often follow a "patron-client" approach.

\section{Problems at the application stage}

Although the workshop discussions focused on the barriers at the level of research and communication, several participants pointed out problems at the application stage. Even when research addresses a critical problem, results are appropriate and are communicated to the potential users, they may still not be adopted. Potential adopters may have objectives not initially taken into accountin the design of research. Alternatively, by the time research. results are available, a variety of factors may negate their successful application. Such problems are not unique to public sector research alone Even industry-managed research suffers from such problems. Garcia described cases where new technologies could not be adopted due to resistance from workers. Instances where new technologies became outdated due to introduction of new processes were also noted.

The low rate of adoption of research directed at improving forest management was attributed to the lack of interest by forest managers. Traditionally, forestry services are geared to enhance revenue to governments and to supply wood to industries. When these objectives can be reached by harvesting natural forests, the incentives to apply new techniques are limited, especially if they are perceived as not contributing to the immediate objectives. As pointed out by Salleh this has led to a feeling among forest managers that they can manage the forests without any research inputs. 
A substantial amount of research, especially during its initial stages, does not produce results which are of immediate value to forest managers and other potential users. Often, users are interested only in readily applicable and proven packages. Drawing on experience from tree breeding, Katerere pointed out that clients, although they recognise the benefits of research, are not prepared to pay for all the basic research leading in its final stages to the development of improved seed sources. This is an important issue to be considered in re-orienting research to make it more responsive to the demands of users. The question was raised of the possible effects on basic and strategic research if there was no well-defined client willing to pay for such activities.

\section{Response to the problems: case studies}

Case studies from Australia and New Zealand (Rawlins and Devine) provided some insights into the transition to a demand-driven research system and how collaborative arrangements with various stakeholders can be operationalised. As indicated by Devine, an important point of the Integrated Research Funding System in New Zealand is that the priorities for funding of particular science areas are determined by national goals, not provider needs. That is, individual researchers, research institutions or government departments do not set their own priorities. Rawlins and Devine both stressed that basic research does not appear to suffer from these new research prioritisation and funding mechanisms. However, it is unclear whether national goals are identical with the goals of individual user groups. In many developing countries, national goals conflict with the goals of rural communities. In attempting to design more effective research systems, this aspect needs further attention. This is particularly true if the interaction between researchers and research users is to be altered from a prescriptive one to a participatory or even a catalytic one, in which researchers become facilitators and research builds on an informal indigenous research tradition. Wong described the changes in the structure of the Forest Research Institute Malaysia and how it facilitated better interaction with a wider group of research users.

Industry representatives (Pinso and Garcia) presented a contrasting situation and brought out clearly the differences between private and publicsector research. Barriers rampant in public-sector research in many countries appeared to be irrelevant to industry-managed research. The latter is more application-oriented and undertaken with well-defined objectives. Once management perceives a problem, researchers are hired to investigate the problem. Output, if found relevant, is directly used, and barriers at the application stage are negligible. Problems arise only when external factors make the results irrelevant, as in the case of emergence of new product or cheaper technologies.

While industry-supported research has a number of advantages, it is not a model that could be widely applied without modifications. Limited and well-defined objectives, full commitment of management, and adequate funding are major advantages. Also, it must be borne in mind that much industrial research relies on basic knowledge derived from public-sector research. In contrast, public-sector research faces a complex situation, with a multitude of objectives, diverse interest groups, and resource constraints. The industry model also is of limited relevance in overcoming problems faced by the large number of small enterprises and farmers. However, this does not mean that public-sector research shouldnot look more closely at viable models for demand-driven research, as indicated by Devine and Rawlins.

\section{Where do we go?}

There has been broad understanding as to why research is still predominantly supply-driven when in actual fact a demand-driven research agenda would lead to less irrelevant, though not necessarily more innovative, research. In lowering the barriers to the application of research results, much can be learned from recent experiences in market-driven or contract research and from experiences of forest industries. At the Workshop, examples were outlined to illustrate the advantages of contractual arrangements between researchers, and mechanisms for increased collaboration with clients. Negative impacts of such systems on those who are unable to pay for research, such as the rural poor, or those whose views can presently not be heard, such as future generations, were also recognised However, the consensus was that the current mechanisms for identifying appropriate research issues are weak. If our goals are to enhance the capabilities at the field level and for limited financial support to be used more effectively, the proper identification of issues and problems needing research attention cannot be left to either researchers or clients alone. 
Enhancing the capabilities of research systems requires efforts of all interest groups. Researchers and research managers must assume responsibility for revitalising research. Several speakers emphasised the need for identifying the potential research users, their problems, needs and aspirations and to find those whose problems are not being addressed. Corresponding responsibilities can be assumed by policy makers, donor agencies, forest managers, extension workers and other such stakeholders. The need for altering the research process and modifying the system of accountability and rewards was also stressed by several speakers.

The challenge is to develop a system which does not only allow for well-funded clients to actively participate in research, but which allows those user groups who traditionally have relatively poor access to public-sector research, whether they are farmers, foresters or managers of small-scale wood industries, to become involved in problem identification and research design. As Katerere pointed out, rural communities should be encouraged to identify their research agendas, and, if necessary, mobilise financial resources and then pay for the research they identify as a priority.

\section{Concluding remarks}

A review of the objectives which the workshop organisers had set (See page 2) indicates that they were perhaps too optimistic. Discussions and presentations focused predominantly on the first two objectives of identifying barriers and assessing current strategies for setting research priorities. Too little time was spent developing a strategy for overcoming the barriers at different levels. There was a general consensus that the four causes which make up the main body of this report constitute also the main barriers to the application of forestry research results. That, however, does not imply that there was a general agreement on their relative importance. Participants were invited because of their different backgrounds and experiences. Therefore, it was not surprising that they assessed the magnitude and the importance of the iridividual barriers differently. For the most part there is no doubt that we will see perceptible increases in adoption rates of new technologies, management practices and policies only if changes occur in all of the barriers discussed.

\section{Some qualifying observations}

The authors of this Workshop Report would like to add the following qualifying observations to this last assessment.

It is obvious that some prospective research clients have difficulties in applying research results. However, researchers and extension workers should scrutinise very closely whether it is just a matter of finding and offering the right set of incentives to increase adoption rates, or whether the disseminated innovations are appropriate.

Ineffective communication of research results by extension services received considerable attention. Clearly, there is room for improvement. In particular, the one-way flow of information needs to be overhauled and replaced by a two-way exchange. Notwithstanding the deficiencies that do exist at present, it should be apparent that even the most effectively functioning extension service is powerless if what is to be disseminated creates more problems than it solves. This is not only frustrating for prospective users but for extension workers themselves.

Numerous problems could be avoided if the actual research was conducted in a different way. This includes close collaboration between researchers with varied expertise, the recognition that many problems require inter-disciplinary research, the belief that close participation with the ultimate client is a must, and the acceptance of informal research and local knowledge as part of science. However, it must be realised that mere participation of users in research activities will not achieve the desired results if problems are not identified appropriately.

Hence, conventional efforts to lower the barriers focusing on improved communication and extension, modifying the research process and even permitting a certain degree of participation by research users alone may not have a perceptible effect unless the very issue of problem identification is effectively addressed. This is by far the greatest challenge to researchers and research institutions. During the workshop the supply-driven mode of research, attributable often to a paternalistic approach to problem selection and definition which neglects the demands and needs of clients, received considerable criticism. The threat to the status quo was identified as a major constraint in bringing about changes 
towards a more client-driven research. Perhaps change should not be viewed as a threat, but rather as an opportunity and a challenge. Funding restrictions may impede needed changes, unless researchers are able to signal to the stakeholders that what is done is for their ultimate benefit.

Therefore, it appears to the authors that new strategies have to be developed for identifying researchable issues, setting research agendas, allocating financial resources for research undertakings and for enabling the potential clients to make their voices and concerns heard. Experience in New Zealand and Australia provides valuable lessons for developing systems appropriate to each situation.

The workshop on Barriers to the Application of Forestry Research Results was only an initial, but important, step in developing an applicationoriented research framework. The removal of barriers requires consistent action at all levels. Notwithstanding the differences in views on the significance of different barriers, the very recognition of their existence and the need to remove them itself constitutes an important achievement. While research environments and systems in the countries of the region are diverse, there is considerable scope for learning from each others' experiences through continued dialogue and discussion.

This workshop report is intended to facilitate and stimulate such discussions. We plan to follow it up with a working paper on developing more effective research strategies. This will be circulated widely for feedback from interested members of the research and the research user community. The working paper should serve as a basis for further deliberations and for eventuully forming a dialogue group to promote efforts to overcome - or at least minimise - the barriers outlined above.

Acknowledgements. The authors are grateful to the Asian Development Bank, and the United Nations Development Programme for their financial support without which it would not have been possible to organize this Workshop. Assistance provided by the Australian International Development Assistance Bureau and the Government of Netherlands by way of funding participation is gratefully acknowledged. The authors also wish to express their gratitude to Jon Anderson and Francis Ng for their comments and suggestions. 


\section{Appendix 1- List of Papers and Abstracts}

1. Opening address: Science, innovation and forestry: What is wrong with forestry research?

M. N. Salleh

2. Keynote address: Rural poor, empowerment and forestry research.

A. Z,M, 0 baidullah Khan

3. Now you see it, now you don't: The effects of the "Ecocrisis Theory" on research Thomas Enters

4. The barriers to and strategies for application of forestry research results in China

Hong Wang

5. Strategies for Overcoming barriers in the application of forestry research results in Vietnam

N guyen Huy Dzung

6. Barriers to application of forestry research: The case of Sri Lanka

H. P.M. G unasena

7. Notes on barriers to forestry research

\section{Edgar Viquez}

8. Application of forestry research results in Bhutan: Potential and constraints

M. R. Moktan

9. Barriers to the application of forestry research results in Nepal

\section{Rajendra B. Joshi}

10. Barriers to the application of forestry research results in India

\section{V.K. Bahuguna}

11. Barriers to the application of research results in the development of non-wood forest products

Wanida Subansenee

12. Overcoming barriers to the application of agroforestry research results: Perspectives from the AsiaPacific Agroforestry Network

\section{Chun K. Lai and James H. French}

13. Forestry research - Evolving the Brontosaurus

Doug Las R. Henderson

14. Barriers to the application of forestry research results: Zimbabwe Experience

\section{Y. Katerere}

15. Forestry research result barriers in practice

\section{Sudijono}

16. Barriers to the application of forestry research results: The PRI Experience

Mamerto L. Garcia 
17. A case study of barriers to the application of forestry research results

Cyril Pinso and J. Tay

18. Barriers to the application of forestry research results: The perspectives of funding agencies

Barin N. Ganguli

19. Land use research and extension in Vietnam

Houng Hoe

20. The barriers to the application of research results of exotic forestry in China

Wang Huoran

21. Barriers to application of forestry research results: A Malaysian NGO Perspective

Gurmit Singh K.S

22. Barriers to the application of forestry research results: Recent Australian Experience

Bill Rawlins and Alan Brown

23. Organisation of forestry research and development: The Malaysian experience

Wing Chong Wong

24. The New Zealand experience of an Integrated Research Funding System with particular reference to the forestry sector

Sean D evine 


\title{
Opening Address: Science, Innovation and Forestry: What is Wrong with Forestry Research?
}

\begin{abstract}
M. N. Salleh
A quotation from C.F. Kittering reads: "We can communicate an idea around the world in 70 seconds; some say less than that, but sometimes it takes years for an idea to get through a quarter inch of human skull." What this implies is that what ultimately matters is the human mind which can be a great barrier to accepting change.

Human history is replete with outstanding individuals who have changed the course of civilization. Aristotle, James Watt, Thomas Edison and Alexander Bell are four such inventors. Aristotle's ideas and theories have left a lasting imprint on every major field of philosophy and science. Watt was the inventor of the first practical steam engine which accelerated the pace of global development. Edison invented objects that he expected to be readily marketable. He was also a manufacturer and an entrepreneur, and established what eventually became the General Electric Company or GEC. Bell invented the telephone, which he patented. He also formed a company which was the ancestor of AT\&T, the American Telephone and Telegraph Company, one of the largest corporations in the world today. These four people changed the course of history. Lessons can be learnt from them.

Aristotle's teachings underpin the need for logical thinking and drastic changes in attitude. There is a perceived belief that anyone can manage a forest. Loggers are not professional foresters and neither are many forest managers. The impacts of forestry often take a long time to manifest themselves and underscores the need for professionalism, responsibility and accountability. It calls for a change in mindset.

Watt was not the first person to invent the steam engine but he improved existing technology and made it practical and efficient. An invention has to be developed, adapted and improved so that others will desire and want your invention. Edison was also very innovative. However, forestry research is not known for innovation. It is too traditional. Measuring trees or plots or the growth of forests are all very useful, but there is very little innovation involved. Greater innovative efforts are needed in forestry research in order to enhance its credibility.

How much forestry research is based on the probability that the output can be marketed? How much market research has been done to determine what the market wants in forestry research?

Team research is another innovation of Edison as well as the development of the prototype for large research laboratories. While lack of manpower and resources are the oft-repeated problems of forestry research, the apparent unwillingness of forest researchers, particularly in developing countries, to work together and share information and effort is of concern.

Both Bell and Edison formed companies to market their outputs of research. The message here is that research must be linked to industry, either through corporation or even privatization if it were to ensure utilization of research results. Moreover, this will ensure a pressure for commercial or market driven research. Currently, all forestry research institutions are public institutions, and there is no pressure to commercialize or be market driven in their research.

Another common denominator of the three successful men, is the strength of science supporting their research. Currently, there is inadequate science in the practice of forestry, even though forestry is considered a science. Another characteristic of the individuals, is the profuse output of research, although only a small portion is commercialized. Low output is one of the problems of forestry research, which must be enhanced to enable it to be more productive.

With the global concerns on forestry and the environment, forestry as a discipline is at a cross road. Forestry research as an endeavour is at a critical juncture. We have a long way to go. While fully agreeing to the need to overcome the barriers to the application of research, we urgently need to enhance the quality and status of forestry research, particularly in the developing countries.
\end{abstract}




\section{Keynote Address: Rural Poor, Empowerment and Forestry Research}

\section{A.Z.M. O baidullah Khan}

I feel greatly honoured in being invited to address this important workshop on forestry research and its application. Unlike the usual research meetings, participants include not only leading researchers and research managers, but also various other stakeholders, NGOs and forest managers; industries and donor agencies; extensionists and public interest groups. The idea is to have a broader perspective, so that technology is integrated with social practice. Ideas and concepts do not come from heaven nor do they fall from the sky. They come from social practice.

And that is what I would like to draw your attention to - science and technology as integral to indigenous knowledge and its role in empowering the dispossessed of the earth. Researchers often distance themselves from such issues as they are considered to belong to the domain of political economy. Unfortunately, technology is seldom politically neutral and development can never be apolitical.

Notwithstanding the significant research accomplishments (especially judged on the criterion of number of papers published), a significant segment of the people have been excluded from the "enchanted circle". Such uneven access has often led to transformation of technology into an instrument for dispossessing the disadvantaged. Traditional biases in resource use with emphasis on consumer culture have resulted in technologies that short-change the rural poor as well as the new poor, namely nature.

Take the case of shifting cultivation, an important form of traditional land use by the resource poor ethnic groups. The dominant thinking has treated slash-and-burn as the major cause of tropical deforestation leading to prescriptions for more settled systems and incorporating the indigenous communities into the "mainstream economy". Failure of this approach and the better understanding provided by anthropologists and ecologists have softened the criticism of the so-called backward mode. Nevertheless, appropriate technologies that incorporate and improve upon traditional know-how of swiddeners are far from available. The taungya system introduced by the colonial forestry departments and its modern-day versions of agroforestry are yet to address the problems in their totality. Measures advocated now have often undermined the genetic diversity of the forest ecosystem and, in the process, the livelihood and the cultural heritage of the communities.

Examples of community-managed conservation efforts are widespread. Some of the hill tribes in southern India are reported to use more than 200 plant species as food, medicines, fibres and cultural Artefacts. Local cultivars of important crops like rice are maintained in community gene banks. One of the finest example of community-managed forests is that of the Damar gardens in Sumatra. Home gardens in Bangladesh provide as much as $80 \%$ of the bamboo and fuelwood supplies in the country, while forests which are supposedly managed with all the technological inputs are off limits for the local communities.

There are many other examples of community efforts to conserve and manage resources. An interesting one is the widespread planting of neem by the Housa tribe in Sub-Saharan Africa. Although not indigenous to Africa, the technique of propagation and management of neem has been so perfected that every Housa village can be spotted from a distance by the lush cover provided by neem trees. Even in the most inhospitable locations, the Housa people plant neem, justifying the saying that "where there are Housas there are neem trees". While foresters are still grappling with the problem of germination of neem seeds, the Housas are conversant with every aspect of growing and utilisation of neem.

Protection of relic vegetation as sacred groves is an integral part of the culture and belief of many communities all over the world. The "dos and don'ts" pertaining to their protection cannot be dismissed as unscientific. On the contrary, they reflect a deep-rooted conservation ethic, conveyed through religious beliefs for wider compliance. Notwithstanding the erosion of traditional beliefs and the decline in the standard of protection, some of these sacred groves still harbour species that have long disappeared from the surrounding landscape.

These examples indicate that people have been managing resources with whatever know-how they have acquired or developed through social practice. No doubt the level of technology requires substantial upgrading/adaptation to respond to changes, especially population growth, increased levels of consumption 
and so on. Yet most of the current efforts are directed at superimposing new technologies, whose organic linkage with pre-existing knowledge and experience is very limited. To me this is one of the major barriers to research application. Neglect of the cultural dimensions and traditional value systems accentuate the problem of application and adoption.

I am not valorising the noble savage and traditional knowledge by themselves. All that I want to emphasise is the incorporation of frontier science into local knowledge.

Let us dispassionately consider who influences the agenda for research and development in the forestry sector. Historically, commercial and trade interests (from within or outside the country) have exerted tremendous demand pull on research, resulting in emphasis on utilisation, inventory, establishment of man-made forests and other allied activities. Silvicultural research, for example, has been primarily directed at commercially important species and, in particular, those that could be grown as large scale monocul tures.

The need for ensuring adequate supplies of industrial wood has resulted in a range of technologies, which has more often than not reduced the inherent biodiversity of tropical forests. Ironically such decimation has been justified under the pretext of forest conservation.

Products which are of no immediate commercial consequence, but of considerable subsistence value to local communities, are lumped together as minor forest products. As the late Dr. Y.S. Rao has pointed out "these have been relabelled" as non-wood forest products for "reasons with more potent logic than simple addiction to semantic nuances". Recent interest in non-wood forest products has been due to the realisation of their immense commercial and industrial potential. Will this broadened interest help the local communities? Will they have any control over the vast genetic resources with which they are familiar and which they have been utilising for centuries?

There are reasons to believe that this will not be so and it is quite possible that access to these resources by local communities will be curtailed. International patent laws will favour those with resources, scientific know-how and lawyers. People's knowledge can be easily dismissed as folklore, while the same information couched in scientific terms will pass as discoveries justifying claims under the patent laws. The end result is evident: traditional users/collectors will not have access to their own knowledge resource and at best they will be utilised as wage labourers; a repeat of the history of plantation development in the tropics.

History of forest management is replete with such resource use conflicts. Whether it is the agitation of the forest-dwelling tribes in the Chotanagpur Region in India against planting of teak, clearfelling the natural sal trees or that of the Thai farmers against planting eucalyptus, or such other instances throughout the world, the basic issues are the same. Communities with deep-rooted traditions of conservation have been exiled from their natural habitat. Predatory greed of the powerful and subsistence need of the powerless have resulted in continued destruction of our natural resource base.

This brings me to the equity issue underlying development of technologies. Given the inequitable distribution of wealth in society, technology is seldom a neutral tool for all humanity. Unless a conscious effort is made, it could, and often has, become a powerful mechanism for exploitation of the disadvantaged and the disfranchised. Technological developments are appropriated by those who are resource-rich and therefore powerful. The poor and the women are excluded. In fact poverty is the end result of exclusion from institutions and resources that are necessary for leading a life with dignity.

Now that the market is king, these tendencies are getting more pronounced. Structural adjustment, liberalisation and market orientation are the key words in the current economic development discourse. Considerable emphasis is being given to user-oriented and user-paid research. Research institutions are increasingly being pressurised to earn their resources through contractual arrangements. While this has certain advantages - in that research becomes more outcome-oriented - it has also serious negative impacts. Undue emphasis on user-paid research will distort priorities and the needs of those who are unable to pay. Members of the future generations, who are not represented in the present market place, will be short-changed.

Barriers to adoption of technological developments are not just a question of finding the right kind of extension messages and providing appropriate inputs, credit and such other supportive measures. 
Paternalistic approaches seldom lead to the process of empowerment of the rural communities. It often promotes nothing more than dependency - dependency on external inputs, on outside knowledge and on a new elite who controls such knowledge.

Science is for the emancipation of mankind. It is for creation of a world, where if I may quote Rabindranath Tagore:

"knowledge is free; where the world has not been broken into fragments by narrow domestic walls ... and where the clear stream of reason has not lost its way into the dreary desert sand of dead habits."

Scientists, who have taken the Hippocratic oath have a bounden duty to work for the people and on their terms, not as dispenser of superior wisdom, but as co-worker in creating common wisdom to match our sciences. Let me conclude this with a quote from the late Dr. Y.S. Rao, one of the most eminent foresters of recent times:

Our quest should be directed toward discovering and rediscovering the cultural memory and the nature of dependence of forest communities on forest resources and how we can foster a new and shared consciousness about wise use of these resources. If we assume that the relationship between these forest cultures and nature around them is governed solely by the exigencies of need, such understanding could be characterised as shadowy and partial. For at least some of these communities, the forests and the sacred trees they contain serve as images of the cosmos, symbols of the inexhaustible source of life's force. 


\section{Now You See It, Now You Don' t: The Effects of the "Ecocrisis Theory" on Research}

\section{Thomas Enters}

In setting research agendas, decisions to support or select a particular topic are influenced in the first instance by information from which various actors involved in research draw their conclusions. In whichever way the information is presented, it provides the impetus and the legitimisation to set activities into motion. For research, it serves the purpose of proposing projects and freeing resources for activities. Numerous examples exist which show how the dissemination and use of misperceptions and misinformation, including scholarly writing, have shaped research agendas and affected research activities. Some widely accepted assumptions colour the research and diffusion process, and some act as barriers to the adoption of research results. For instance, farmers are often presented as helpless agents whose only reaction to a problem is to consult an extension worker. However, farming systems around the world are constantly being adapted in response to changing conditions. Farmers are capable not only of devising viable solutions to problems based on their understanding of local conditions, resource availability and their needs, but also of conducting relatively sophisticated experiments. It is a fallacy to assume that farmers have not come to terms with the dynamism of environmental and socioeconomic constraints and opportunities because this is the essence of farming. Nevertheless, farmers are still described as primitive, or at least traditional, in a sense which is the opposite to innovative and progressive.

The "ecocrisis theory" combines research results on diminishing fallow periods, declining crop yields, increasing rice deficiency, poverty, soil erosion, deforestation, flooding, etc. to construct a horror story which may or may not be true. What is clear is that the relevance of the information and the reliability of data used are rarely verifiable or questioned; it is all too often accepted as fact. As a result, causes and consequences of allegedly observed processes are misinterpreted or described in misleading ways. The survival of ecological and social crisis theories is ensured as long as they serve to justify intervention. Furthermore, the "ecocrisis theory" explains that resource conservation research is client-driven. But the client is not the land manager, the target population, the potential beneficiary or adopter. Instead the agenda is development, and the research priorities are set by a different group of clients, mainly researchers themselves, urban decision makers and the international development community.

It appears that there are few rewards for conducting applied, on-farm research in response to managers' needs, particularly the needs of poor, remote land managers, i.e. the upland farmer or shifting cultivator. If anything, the reward system favours those who conduct high-tech, publishable research, even if it is irrelevant. In investigating the persistence of barriers, the questions that deserve answers are why researchers are busy defining problems which suit their own research interests and their solutions, and why they often benefit more from the research results than do the people who are named in research proposals under "objectives" or "target community" but otherwise forgotten.

\section{The Barriers to and Strategies for Application of Forestry Research Results in China}

\section{Hong Wang}

Since the 1950s, results from more than 3,000 forestry research studies have been produced in China, but only about 30 per cent have been applied in the production sector. Many problems have arisen in basic and applied research, as well as in the demonstration and transfer of the technology produced by research which can ultimately bring economic and social benefits. First, when new projects are proposed by researchers and the proposals reviewed, there is little, if any, input from production-sector specialists. This means that the results do not meet the needs of production units, i.e. the research is not relevant or useful to the users. Furthermore, because benefits in forest production take a long time to be realised, adoption of new techniques is slow. There are no direct and immediate economic benefits to encourage adoption. Another 
reason for the failure to apply research is the inadequate demonstration of results before they are used on a large scale. Basic theoretical research receives only about 6 per cent of all forestry funding in China which is insufficient to provide a sound basis for future applied research and technology transfer.

There is another type of problem relating to technology transfer. As yet, computers are not used extensively to manage and communicate scientific information in China. Thus, the rate of technology transfer is slow and the application of research confined to areas close to where research is conducted. The target group for extension of forestry research results is the forest workers and peasants involved in basic production. Theusually need assistance to understand and apply the modem technologies of production. Often science and technology management organisations pay more attention to production of publications and scientific papers than to training and education for successful application and extension of results.

Strategies for improving application and extension of forestry research results include: i) strengthening communication between research institutions and the production sector to ensure that research projects directly address forest management problems; ii) establishing an efficient extension network responsible for technology transfer and application; iii) standardising procedures for testing and demonstrating research results on a small scale in different regions before extending them to larger areas; iv) prioritising the application of research results that can achieve obvious economic benefits as well as research results which have obvious ecological, but no direct economic benefits; v) paying more attention to basic research which is the foundation for future technology development; and vi) setting up a foundation to financially reward scientists and extension staff for successful application of their research results.

\section{Strategies for Overcoming Barriers in the Application of Forestry Research Results in Vietnam}

\section{Nguyen Huy Dzung}

Vietnam's forest management is organised in a hierarchical system with state government at the top, then the provincial forest departments, and finally grass-roots units at the district and commune levels. Forestry research is conducted in a number of research and educational institutes but few results have been used in the field because of problems of application and dissemination.

There are several barriers to the flow of research results to the potential users. The results are often complex and impractical when users require only simple solutions. In addition, the traditional knowledge of users is usually ignored by the scientists. Studies have failed to take account of the diverse characteristics and needs of local communities in their daily lives and farming practices, and the fact that their knowledge of sustainable forest management is inadequate. Most research is aimed at the state-run forests management groups with access to large areas of forest. The need for farmers to maintain some short-term income in the early years of a project is not considered in the planning of long-term activities with low priority given to community-based research projects. While forest communities constitute more than 20 million people, including about 3 million shifting cultivators, there are few suitable forest land-use models for these groups. Costs are too high and appropriate technical expertise and assistance is not available to farmers in mountainous rural areas.

In Vietnam, many different groups are involved in forestry research and extension activities. This complicates the organisation of extension services since no single entity has overall responsibility to provide an efficient service. A shortage of extension officers impedes the spread of new technologies further afield, particularly to remote areas. Most models are developed for-more accessible areas where users enjoy favourable conditions and are receptive to new techniques. They are not easily replicable in areas with poor conditions, particularly for impoverished households. Poorly trained extension officers are also unable to adapt a technique to different environments.

Solutions for overcoming these barriers to the application of research results include: i) establishment of a national forestry technological transfer centre to increase the extension capacity, especially of grassroots units; ii) focusing of research on local communities to better understand farmers' needs and socioeconomic conditions, iii) hand over of land and forest resource ownership to farmers to provide incentives for sustainable resource management; iv) improvement of the flow of communication to increase 
feedback between researchers and forest communities; and v) provision of training for extension staff to improve their effectiveness and to members of local communities to act as intermediaries for disseminating technologies to their communities.

\section{Barriers to Application of Forestry Research: The Case of Sri Lanka}

\section{H.P.M. G unasena}

The Forestry Master Plan of 1986 recognised that forestry research had suffered due to a lack of trained staff and poor coordination and continuity of development projects. Forestry research has been a small component of the national research system receiving just 2.2 per cent of the total research budget for agriculture and forestry. However, in recent years substantial funding for forestry research has been made available through foreign-funded projects. Besides the Forest Department, forty-three other agencies carry out forestry research. University-based scientists conduct research on specific areas of interest which may not be practically oriented, but be donor driven or designed for post graduate research, institution building or publication. The work of the commodity research institutions is commercially oriented to solve particular production problems.

The beneficiaries of forestry research include forest-dependent people, forest-based industries, the Forest Department and other sectors such as energy, agriculture, irrigation, wildlife, fisheries and tourism. Primary benefits are the conservation of biodiversity, provision of timber and non-wood products, economic utilisation and sustainable management of natural resources, and control of environmental impacts.

While a vast amount of research data is now available in all areas of forestry, including silviculture, genetics and tree improvement, agroforestry and social forestry, the application of results are hampered by the lack of a direct link between researchers and end-users. This is especially so for university-directed research. General constraints identified by various agencies conducting and disseminating results of forestry research, include: i) lack of trained staff; ii) poor training facilities; iii) insufficient funds for equipment, consumables and transportation to field sites; iv) pressures due to other priorities of institutions; and v) poor career-development opportunities.

The main problems associated with the application of research results include: i) poor dissemination of available knowledge; ii) low acceptance of new technologies because of poor extension services; iii) few intersectoral linkages between extension services; and iv) absence of short-term benefits to encourage endusers' to adopt innovations. Forestry extension personnel are not fully trained in the latest extension methods and may only know about traditional forestry. A 1989 study recommended a unified extension system based on an integrated farming systems approach and to include forestry, crop, livestock and commodity production. The National Forestry Research Committee and the Forestry Technical Research Committee have recently been established to guide and evaluate forestry research in Sri Lanka.

\section{Notes on Barriers to Forestry Research}

\section{Edgar Viquez}

Population growth and the consequent demand for forest products and agricultural land are major causes of the loss of tropical forests. Despite efforts to assess and preserve the resource, sustainable management is, as yet, not possible. Forestry research in Central America is in its infancy and to discuss technological packages for transfer and implementation is premature. Most research has concentrated on biodiversity and, to a lesser degree, silviculture of native tree species for reforestation. The full potential, genetic variation and management of a large number of native species has not been studied.

Identification and implementation of forest research encounters many problems. There is a lack of clear objectives so that research is not target-oriented. Poor links between researchers and with policy makers and donors leads to duplication of effort and waste of scarce funding resources. The lack of trained personnel inhibits the effective implementation of research results. Intense competition for scarce funding 
can result inappropriate projects which are politically popular but not high priority, and also means there are insufficient resources to complete projects effectively. These problems exist in all areas of research

Because forestry is a long-term activity, research results are not available quickly to bring immediate returns to investment. The large area required for forestry contributes to problems of cost, design and uncertainty of conditions. A further, more specific problem is that of guaranteed access to sufficient seeds of high quality.

CATIE has collaborated with national research institutions, as well as with universities and NGOs, to promote forestry and agroforestry research in Central America. It has also facilitated effective transmission of results to farmers. Continued cooperative effort is required in this complex area of forestry research.

\section{Application of Forestry Research Results in Bhutan: Potential and Constraints}

\section{M.R. M oktan}

Forestry research is relatively new in Bhutan. However, with the help of donor-assisted projects, the Forest Research Division has developed to include facilities and manpower to conduct and implement research programs and to train nationals. However, human resources remain limited so there is a continual need to refocus research on the highest priority topics. In addition, forestry research is under-funded, receiving less than 2 per cent of the total Department of Forestry budget, compared to more than 8 per cent of the Department of Agriculture budget being allocated to research. This reflects the relative infancy of forestry in the research sector of the Ministry of Agriculture.

A major constraint to forestry research and its application is that potential users and their needs have not been adequately identified and addressed. Long lags between research and implementation of results, and the isolation of potential users from divisional staff also inhibit application. Priority research activities have been identified through surveys but only for certain clients, notably the Department of Forestry and the Bhutan Logging Corporation. There is little direct involvement of other potential clients, such as farmers, in the social forestry program.

Research information reaches clients through the extension system which used to be a one way flow of information. A new system, operating through Dzongkhag (district) authorities, directly involves the people in planning and implementation of research. Users of forestry research in other divisions in the Department of Agriculture provide inputs and feedback in planning, implementation and evaluation of research activities under the Department of Forestry. However, interdepartmental research centre links are few.

Forestry is a relatively new participant in extension activities, and the Forestry Research Division lacks a strong technology-transfer arm so the production and distribution of material for use in the extension service is not yet adequate. A recently introduced general forestry magazine, "Druk Forestry News", is targeted to extension workers and the general public, where earlier outlets for results were mostly directed at researchers.

The Forest Research Division needs to widen its support base. A research advisory committee with members of clients from government research and extension units and industry would considerably improve planning and priority setting. Linkages could be strengthened through various training programs, seminars, field days and demonstration plots to facilitate effective interaction between research staff, extension workers and clients - the end-users. 


\section{Barriers to the Application of Forestry Research Results in Nepal}

\section{Rajendra B. Joshi}

Forestry research in Nepal began in the early 1970s and was focused primarily to support the public sector forestry program with technical research. The scope has since diversified to include natural forest management, agroforestry and soil and water conservation issues. The target of research is becoming more community forestry oriented.

The primary barrier to the application of forestry research results is the inappropriate identification of research issues because there is little effective communication between researchers and users of results. In addition, the users' needs can be too numerous and diverse to be adequately addressed with limited financial and human resources. Recently, the Forest Research and Survey Centre has been attempting to improve communication with end-users to prioritise their needs by surveys, meetings and informal talks.

The process of research itself is generally isolated from the user. Involvement of the user at this stage could improve understanding by the farmer, reduce financial and manpower costs, and identify possible problems for later adoption. Communication of research results must be in a form understandable to the clients and easily applied. Several methods such as radio programs, leaflets, field training and demonstration plots can be used to show how to apply techniques and explain benefits.

Even if research results effectively reach the users, there may be problems in the application stage. These may be seen in the following forms: i) financial constraints of the end-users; ii) lack of technical knowledge of users; iii) lack of trained and motivated field staff; and iv) inadequate access to markets for new products. A number of government programs have been attempted to lower these barriers to adoption of research results including small farmer loan programs and extension programs.

\section{Barriers to the Application of Forestry Research Results in India}

\section{V.K. Bahuguna}

Barriers which inhibit the application of forestry research results in India relate to poor planning, faulty identification of research problems, lack of involvement of user groups, inadequate funding, poor technology-transfer mechanisms, and lack of techniques to evaluate research impacts.

Poor planning of the entire research process is the major barrier. Planning must be undertaken in cooperation with different users to assess needs and identify ways to apply results in the field. The selection of a research topic is often arbitrary, with no focus on the objectives, methodology and testing of research results. If there is no consultation with user groups at the planning stage, the results are often ignored because they are not relevant to their needs. No mechanisms exist to carry research results to the field for trials and subsequent large-scale adoption. The responsibility for technology transfer should be shared between both the researcher and extension worker by arranging demonstration trials to show the benefits of research results and how to apply them. A lack of commercial incentive to conduct applicable research hinders the selection of appropriate research issues. Research projects are often selected and designed to attract funding for a research institution, rather than fulfil a real need. All research needs to be paid for, good research even more so.

Effective evaluation methods will have the potential to improve resource allocation, planning, decision making, monitoring and overall management of research, and thus remove barriers to the application of research results. The evaluation process should extend beyond research institutions to users of the research. However, the process itself must not become a barrier to conducting purposeful research. Privatisation of research and accountability for results could focus work on practical, user-oriented issues. 


\title{
Barriers to the Application of Research Results in the Development of Non-wood Forest Products
}

\author{
Wanida Subansenee
}

Poor communication between researchers and clients acts as a barrier to the application of research results. The clients, who should be identified before the research is initiated and be involved in planning, generally fall into three groups; i.e. the private sector or forest-based industries, government organisations, and forest dwellers or farmers. Each group has different information needs, The private sector may require hightechnology or industry-oriented information, government organisations need training and extensionoriented information and management data, while forest dwellers/farmers need simple technical know-how on cultivation, harvesting, processing, utilisation and marketing. Feedback is required to exchange ideas and solve problems.

Sometimes, the characteristics of the research itself constitute barriers. If the project is a small isolated piece of research, rather than part of a complete package, it may have no application. Poorly motivated and inexperienced research staff can result in low quality research results and inapplicability; field staff lacking adequate extension skill and experience will not transfer technology optimally. Finally, a suitable funding level and continuity are essential for quality research.

In addition, legal and policy constraints are a factor that slow down the development of non-wood forest products for the forest dweller. Management of non-wood forest products in the forest is regulated by law and Royal Forest Department policy. Permits are required for harvesting protected non-wood forest products. Research and application of results must be consistent with existing law and policy.

\section{Overcoming Barriers to the Application of Agroforestry Research Results: Perspectives from the Asia-Pacific Agroforestry Network}

\section{Chun K. L a i and James H. French}

A framework for analysis of farm-level decision making is proposed, where the farm household is used as the primary unit of analysis based on its unique socioeconomic and biophysical conditions. Agroforestry technology and investment decisions are evaluated based on key factors that influence farmers and agricultural entrepreneurs, including: i) access to markets; ii) access to support services; iii) access to scientific and indigenous knowledge; and iv) influence of policies, rules and regulations. Within this framework, a matrix is presented as a tool for diagnosis of the current situation, constraints and possible interventions.

Structural, disciplinary and cultural barriers that may influence adoption of agroforestry research results are identified. Structural barriers have to do with organisational mandates and territoriality. This is reflected in restricted flow of information and unwillingness to cross institutional boundaries. Discipline barriers concern the way people are trained and how this influences their approach to problem solving. For example, a social scientist concentrates on the people in a forest community, while a silviculturalist concentrates on the trees. It should not be forgotten that farmers are also professionals, trained over generations to hedge their bets between different farm enterprises to ensure adequate security for their families. Cultural barriers derive from rituals, beliefs and values. Indigenous knowledge tends to build upon observations of nature. Scientific hunches tend to be based on deductive reasoning and imposition of assumptions. Extension workers are expected to understand both worlds, but often they get lost in between.

Possible interventions for overcoming these barriers include networking activities to bridge existing gaps, synthesis of existing scientific and indigenous knowledge for field application, and strengthening linkages between farmers, extension workers and researchers.

APAN is a regional network that supports agroforestry interventions at the regional, national and field levels, and examples are provided of APAN approaches and activities to disseminate useful research results. Recommendations are presented to: develop a simple farm-level framework as the basis for possible interventions; formulate networking, synthesis and linkage strategies to support interventions; package 
information to reach farmers, extension workers, researchers and policy makers; and prepare realistic action plans on how various actors can contribute to the process.

\section{Forestry Research - Evolving the Brontosaurus}

\section{Douglas R. Henderson}

The question of barriers to research application can be approached by examining what constitutes forestry "problems", research-produced "knowledge", and the link between the two. Research needs to address high-priority problems before research results can be effectively transferred to those with problems.

Researchers often perceive the barriers to be at the extension level, caused by ineffective mechanisms for transferring results to those who need them. However, this assumes that the problem is adequately understood and is usefully linked to researcher-produced knowledge. If the problem is not well understood, then the process of generating relevant knowledge becomes almost impossible. A major concern is whether the problems perceived and investigated by forestry researchers are the same problems perceived by those who need forest-related knowledge. If the perceptions of the problems are different, then the clients will not find the research results of value and they will not be applied.

Conventional forestry is comprised of 20th-century scientific rationalism and 19th-century bureaucratic organisations overlaid on resource tenure and political arrangements established in feudal Europe. The political form of conventional forestry - an elite force protecting and managing forets estates, unaccountable to local people - is ill-adapted for managing forest resources in the contemporary world, as are the resource management strategies and standard operating procedures which fit this political form.

Community forestry, with a primary focus on people and community involvement, moves some way to solve this dilemma. Four concepts in particular - farm forestry, agoforestry multipurpose trees and shrubs, and non-timber forest products -have gained substantial visibility in recent decades. More recently, the concept of joint forest management, which brings community participation and partnership to traditionally forest-agency dominated management of forest reserves, has received some attention. Strong communication skills are prerequisites for successfully conducting research in this environment of cooperation.

Conventional forestry is in many ways a brontosaurus: it has substantial mass and inertia, but its future is doubtful due to shrinking suitable habitat. If forestry research is to survive and remain' relevant, its task is to facilitate the evolution of conventional forestry to more viable and serviceable forms, which will require: a new forestry paradigm appropriate for landscapes that are highly matrixed by human settlement and for societies embracing democratic values; research designs, techniques, and skills appropriate for community- and people-focused forestry; and incentives that encourage - or at least not penalise - forestry researchers to tackle questions and problems substantially outside the gestalt of conventional forestry.

\section{Barriers to Application of Forestry Research Results: Zimbabwe Experience}

\section{Y. Katerere}

The. principal forestry research institute in Zimbabwe is the Forestry Commission, although other institutions have the capacity to undertake some aspects of forestry research. It is expected to service both commercial and developmental forestry needs.

Research has been plantation driven with a major focus on tree improvement. This sector has been entirely funded by the government. The work essentially formed the foundation for a plantation-based forest industry. Benefits to the private sector are clearly visible. While the industry does not contribute to research costs it readily adopts results and technical developments.

Forest products research, in contrast, is poorly developed. The industry has primarily relied on technology transfer with some limited capacity to test such technologies. The sector consists of the Forestry Commission, universities, NGOs, other development agencies and farmers. Needs are diverse and revolve 
around the country's 11 million hectares of indigenous woodlands and the rural population which makes up 75 per cent of the country's 11 million people. Historically, the needs of this sector have been ignored and, at times, undermined in preference of the formal sector.

The indigenous forests have received attention only to the extent that they were a source of commercial timber. The economic, sociocultural, ecological and biodiversity contribution of the nation's woodlands have been ignored, as well as the needs of the people for food, fodder, construction material and energy. The non-technical issues of tenure, markets, policy, and legislation have been low priority and yet these represent the greatest constraints to sustainable forestry management.

Application of research results has varied from sector to sector. It has been high in areas such as tree improvement where economic benefits have been clearly demonstrated. The development forestry sector has had less success due to inappropriate research, the non-recognition of local-level research initiatives, and unwillingness of government institutions to incorporate these alternative findings into their planning frameworks. One of the major constraints to application is the fact that results are not always user-friendly and, at times, are inaccessible to potential users. Only by knowing and understanding the potential users can researchers identify problems and disseminate results appropriately.

\section{Forestry Research Result Barriers in Practice}

\section{M.Sudijono}

Major timber producers see forestry research as very important for improving forest management and wood utilisation, and reducing the impact of logging in the field. Research institutes and universities usually conduct research on these technical aspects of forestry. It is the private agencies or non-governmental associations who concentrate on the economic and social aspects. All research groups need to plan and implement projects in cooperation with each other in order to generate results which are technically, economically, socially and environmentally appropriate and usable.

Logging concession holders and industries receive many proposals to undertake research in their working areas. The timber company may subsidise part of the cost of the research if it is found to be acceptable. The topics are usually technical, but can include economic and social aspects. To avoid duplication, these applications should be initially screened by the local forestry research institute.

Large companies usually conduct-their own research on specific problems, but smaller companies do not have the required expert personnel. In order to adopt a research result on a large scale, forest concession holders must obtain government approval. This can be a barrier to the application of forestry research results when the government is slow to approve change. Timber companies play an important role in forestry research, but improved links with government, private agencies and the needs of the forest community could help to bring about an improved result for all groups.

\section{Barriers to Application of Forestry Research Results: the PRI Experience}

\section{Mamerto L. Garcia}

PICOP Resources, Inc. (PRI) is a multi-billion peso wood-based industrial complex operating one of the largest fully integrated timber, and pulp and paper mills in Southeast Asia. It produces natural and plantation timber, pulpwood, newsprint and kraft papers, timber and plywood and is serviced by three distinct internal research departments, namely: forest production, pulp and paper research and timber utilisation. Over 40 years, the research units have developed a number of technology packages but many are no longer applicable or have yet to be applied for a number of reasons.

PRI has identified several barriers to the adoption and continued application of their research results. (1) Shifts in product demand may change the business climate before results can be properly implemented and even after application, resulting in no market for the new product. (2) Technology developed through research often becomes obsolete because of the time between development and implementation. (3) 
Cumbersome technology which reduces the output or efficiency of workers may not be adopted in an environment where payment is based on a quota system. (4) Innovations that rely on the use of pesticides are considered an environmental and health hazard. (5) The cost of implementation imposes an important economic barrier to adoption; costs can outweigh benefits to the users. (6) Where adoption of new technologies would cause job cuts, opposition to the new technology will be met at union and worker levels. (7) Uncertainties and risks involved in introducing new technologies will generate resistance to change. (8) Delays in implementation of new technology will be encountered in the initial phase of application when methods are strange to the user. (9) Professional jealousies exist in any organisation and frequently lead to communication problems between higher educated scientists and their superiors. (10) Application of research results can also be affected by limitations of existing facilities which are not suitable for a new product line.

With adequate logistical support, the new management of PRI, hopes to overcome many of the described barriers and provide support for new business projects and unhindered implementation of research results.

\title{
A Case Study of Barriers to the Application of Forestry Research Results
}

\section{Cyril Pinso and J. Tay}

So much science and information has been documented in forestry research that, to the untrained person, applying forestry research may sound easy. This is not so; there are indeed barriers to the application of forestry research results which may stem from weak communication channels and information exchange, language differences and budget constraints.

Innoprise Corporation manages about 1 million hectares of forest concession in the Malaysian state of Sabah for timber production, conservation and plantation. The corporation commits about I per cent of its annual operating budget to applied research aimed at improving current practices, techniques and technologies. This research is conducted on the corporation's own initiative, and in collaboration with numerous external institutions worldwide. In an in-house case study staff members evaluated seven projects with ten research programs based on criteria of relevance of the research, effectiveness in communicating the research results, and the extent to which research results were applied. Analysis shows that one of the more problematic barriers in research is eliminated when research aims are clearly defined and prioritised. Communication of research results can be hampered by the commercial need to restrict access to new technologies. It is also imperative that research results be communicated in language understood by the users of results.

Most of the research used in the case study is still in the implementation phase and evaluation of effective application is therefore premature. In addition, some of the research has been terminated because of technical constraints, even though the research objectives were highly relevant. Even in one organisation, it was found that proximity, access, language, storage and retrieval of information and people themselves can all create barriers to effective application of research results.

Barriers to the application of research results can be minimised if research activities are geared towards solving real problems. This means that they must be adequately understood and analysed by the appropriate personnel equipped with sufficient financial resources. These are the very essential ingredients to bridge research and corporate objectives.

\section{Barriers to the Application of Forestry Research Results: The Perspective of Funding Agencies}

\author{
Barin N. Ganguli
}

Barriers do not only exist to the application of research results but there are also barriers to international funding of forestry research proposals. Three questions arise: i) do the countries in the region have research proposals which conform with the perceptions and goals of the funding agencies? ii) if not, what are the 
constraints? and iii) how can the research proposals be made more relevant and consistent with the emerging perceptions of the sustainable development paradigm which should be people-oriented, environmentally sound and participatory?

In order to reduce or remove the barriers to funding of forestry research, projects need to involve the users in selection of problems, operation of research and implementation of results, and how proposals are derived. There is great variation in the way different countries approach these issues. Initial preparation of proposals may be by an independent authority, then sanctioned and issued by a national government; but in most countries, proposals are prepared by the forestry departments and hence do not have broad support. In most countries, research proposals are still supply-driven, although attempts are being made to include a larger number of stakeholders through proposal-approving committees. The concept of privatisation of forestry research is missing.

Most countries are just beginning to acknowledge the current international attention on the "common themes" of environment and participation of stakeholders. Implementation of research results is generally ineffective and proposals are supply, not demand, driven. A further important barrier to attracting funding is the present poor overall formulation and justification of projects by most national research systems.

Based on the above, a strategy can be developed to improve access to research funds from bilateral and multilateral funding agencies. Forestry research proposals should be multisectoral concentrate on common themes; recognise the multiple stakeholders; they should be prepared in a modified logical framework format. Further, they should consider the following facts: forests have significant economic, social and environmental values; forests are a renewable resource; any research proposal must recognise and duly support the identity, culture and rights of the forest resident communities; the role of planted forests as sustainable and environmentally sound sources of renewable energy must be recognised; the vital role of forests in maintaining transnational biodiversity values and in acting as a global carbon sink must be recognised. Research to encourage preservation of old-growth forests, to promote designated conservation areas, and to protect unique ecosystems should have priority.

\title{
Land Use Research and Extension in Vietnam
}

\begin{abstract}
Hoang Hoe
The top priority of forestry activities in Vietnam is forest protection and the regreening of barren land. The forestry sector is moving from the old controlled planning mechanism into social and community forestry, which encourages the participation of local people in forest protection and management. The main restoration activity is allocation of land and forest land to households. Over the last few years millions of hectares of land and forests have been allocated to farmers in upland areas. The forestry extension serv ce plays an important role in assisting households in effective land use and forest management to. derive maximum benefit, including environmental protection.

The Land Use Working Group was organised in 1991 to undertake inter-disciplinary research on how individual farmers, communities and state organisations allocate and use rural land, and to provide policy advice on measures that could help farmers increase returns to land and sustainability of land use in the market economy. The main users of policy research are expected to be not just at the ministry and provincial levels, but also the farmers: A major problem is how to organise research activities and how to apply their potential results. This can be facilitated by strengthening communication lines between scientists, policy makers and users.
\end{abstract}

\section{The Barriers to the Application of Research Results of Exotic Forestry in China}

\section{Wang Huoran}

The Forestry research and extension service in China is organised at three levels: national, provincial and county. The agenda of the MOF and Chinese Academy of Forestry is to carry out national priority 
programs, while provincial research institutes of forestry concentrate on regional problems and adaptive technology. The local forestry extension stations provide technical support and extension of results.

It is estimated that about 60 per cent of research results obtained from research projects undertaken by the Chinese Academy of Forestry have been transferred to practical forestry. Government policy specifies that research must be closely aligned to forestry practices. A research project should reach proposed objectives and contribute to forestry development in technical, human resources and capacity aspects. The key to a successful project is effective application of results. This depends on communication of the results to the users by extension.

Forestry extension is made up of an extension office under the Division of Science and Technology, MOF, and, forestry extension stations in each province. To facilitate extension, MOF has established four experimental areas which are located in major commercial forest regions with different ecological conditions for pilot trials. Constraints to effective forestry extension exist in terms of poor funding, in ufficient trained staff, scientists who have not fully adapted to the market economy, and forestry policy makers who are poorly equipped for long-range planning. Research also needs to be appropriate and relevant for implementation.

\section{Barriers to Application of Forestry Research Results: A Malaysian NGO Perspective}

\section{Gurmit Singh K.S.}

Malaysian non-governmental organisations (NGOs) working in the environmental field have generally had difficulties in accessing local research findings in their areas of concern. This has been due to a number of reasons, including the unwillingness of researchers to share their findings, the limited accessibility of some data due to the Official Secrets Act, and the long lag period before the results are available through scientific journals.

The Environmental Protection Society Malaysia (EPSM) was established in 1974. It has been instrumental in raising environmental awakeness as well as launching campaigns with other public-interest groups on such issues as anti-logging, noise and air pollution, dams, human rights and conservation.

Quite often, NGOs have found that essential research on areas of concern has either not been carried out or the result are completly inaccesssible. Exsamples where forestry research results were directly relevant to environmental issues were the Endau Rompin Tembeling Dam and Bakun Dam campaigns. In the context of the climate change debate, there seems to be little primary data available relevant to the role of Malaysian forests compared to other land uses. Access to academic research results is often delayed or denied by lobbying, publication priorities and controversy.

Another problem is that many studies are conducted with a focus on minor or less-pressing issues, particularly in the field of environment and sustainable development. Part of the fault lies with lack of initiative or innovation of researchers who prefer to avoid new areas of potential sensitivity.

The role of foreign scientists in research and local availability of their results is also an issue of concern. Local decision makers often seem to pay more attention to their advice and research than to those emanating from their own citizens.

From EPSM' s viewpoint, research needs to be holistic, problem-driven and anticipatory of potential problems. The fact is, that neither research nor advocacy can be conducted in a vacuum. For both to be effective, persons involved have to demonstrate a high level of integrity and follow a meaningful code of ethics. In the ultimate analysis, the public good must be the determining factor and environmental quality enhanced. 


\title{
Barriers to the Application of Forestry Research Results: Recent Australian Experience
}

\author{
Bill Rawlins and Alan Brown
}

Australian public sector research has undergone a number of changes in the last six years aimed at improving links with research customers and hence the effectiveness of research and the speed and extent of its application. The application of research results has been an issue for the Commonwealth Scientific Industrial Research Organisation (CSIRO) and Australian research generally across the breadth of its interests. Since about 1988, all public sector research has seen changes principally designed to improve its contribution to industrial growth. Today, CSIRO forest research finds itself under pressure to attract more non-government funding and become more involved with industry. This is at a time when the forestprocessing industry is uncertain about investment and is reducing costs including expenditures for research. At the same time questions of sustainability are emerging which must be considered.

Since 1990, CSIRO has been developing a method for setting research priorities aimed at making research more relevant to the well-being and economic prosperity of the nation. The method assesses research priorities based on four key criteria: potential benefits, ability to capture the results, R\&D potential and the ability to carry out the research. Research clients have been involved in the process of selecting priorities to enhance the feeling of ownership of research. A most important part of the process is the questioning of CSIRO's ability to capture the benefits from the research. This requires early identification and rejection of inappropriate projects.

One major outcome of the recent interest in overcoming the barriers around R\&D institutions is an initiative known as the Collaborative Research Centres Program. It is designed to promote links with commercial and government users of CSIRO's research and promote cooperation in the process of research and management of the centres. The Forest and Wood Products Research and Development Corporation was also established in 1994 with cooperation between federal government and forest-based industries.

The latest emphasis is on facilitating the application of research by smaller companies who traditionally have had relatively poor access to public sector research. Accommodation of more changes in the structure of research must be considered in the light of its possible effect on quality of research, Recent efforts to improve the choice of research problems and implementation of results will continue to be assessed over the next five years.

\section{Organisation of Forestry Research and Development: The Malaysian Experience}

\section{Wing Chong Wong}

Forestry research and development in Malaysia was carried out by the Forest Research Institute (FRI), Kepong, a relatively small research unit within the Forestry Department, Peninsular Malaysia, from 1918 to 1985. The Forest Research Institute Malaysia (FRIM) was then established as an independent statutory body to take over the responsibility to conduct forestry $R \& D$. This change was recognised as a positive response to the call for greater $R \& D$ inputs to develop indigenous technology to manage and utilise national forest resources sustainably. With the enhanced status accorded by the government, FRIM has had to reorganise itself to effectively address the complex problems related to the sustainable management of both the forest resources and the wood and non-wood forest products within tropical forests. As an independent R\&D institution, FRIM has to serve a wider clientele even though the Forestry Department remains its most important client.

FRIM has adopted the mission "to promote the sustainable management and optimal utilisation of forest resources by generating knowledge and technology through research, development and application". To give specific attention to environmental issues and to recognise the growing importance of forest plantations, two new research divisions were created. After nine years of operation, the most significant 
change has been the improvement of research capacity. FRIM made the development of human resources a priority task and organised its own training policies as well as supporting outside and foreign training.

Two other features indicate the progress FRIM has made since it became autonomous from the Forest Department. Its board has established a Research Advisory Committee, which comprises local and foreign researchers and industry representatives, who advise on research direction, policies and programs and evaluate research outputs. In addition, it increased its visibility both locally and internationally through close working relationships with the media, local institutions and active participation in conferences, in Malaysia and overseas. As a result the demand for services from the private sector has increased.

FRIM has not only to satisfy the expectations of its relatively new role but also prepare itself for the future. A contract research system has been introduced as one measure to respond to the demand in the country for greater accountability of institutions in their use of R\&D funds. The purpose is to facilitate the effective transfer and commercialisation of research results as well as their application to contribute to national development and enhancement of the quality of life of the citizens.

\section{The New Zealand Experience of an Integrated Research Funding System with Particular Reference'to the Forestry Sector}

\section{S.D. Devine}

When New Zealand faced increasing economic problems in the early 1980s, the value of scientific research as a means of improving economic performance was questioned. Despite significant government investment in research, there appeared to be little commercialisation or implementation of the research by the sector of the economy that would be expected to benefit. In this climate, an analysis of the barriers to effective research implementation was undertaken in 1989 by the Science and Technology Advisory Committee (STAC). It identified problems not necessarily specific to the forestry sector. Because government departments advised on science policy, there were concerns that they captured funding based on their own, rather than the national, interest. The funding levels in different areas were driven more by history and past bureaucratic power struggles than a forward-looking analysis of the national needs. On the other hand, the private sector tended to view research as the responsibility of the government rather than a core part of their business strategy.

The STAC proposed a radical reform of the public science system, designed to integrate research and its implementation into a holistic framework based on the needs of each socioeconomic sector. One intent was to promote partnerships between public and private bodies enabling research organisations to operate on a commercial basis and develop customer relations with users of research. Important features of the reforms were the shift in focus from input to output funding on a fully costed basis and the focus on bridging the gap between research agencies and the commercial sector. While government does not specify projects to be funded, a specialist panel does advise on more macro-funding levels for different socioeconomic sectors. This has resulted in the priorities for funding of particular science areas now being determined by national goals, not provider needs.

While it is too early to measure the effectiveness of the science reforms, a number of factors indicate that some critical barriers to research implementation have been overcome. Both government and industry are now defining their research requirements and priorities in a way that allows researchers to focus on national goals. The research culture no longer exists in isolation from those who will benefit from it. The forestry sector in particular has already developed effective relationships between researcher and user, and indications are that these are strengthening. 


\section{Appendix 2 - List of Participants}

\section{Australia}

\section{Bill Rawlins}

Division of Forest Products

CSIRO Division of Forestry

Private Bag 10

Clayton, Vic. 3168

$61-3-542-2223$ fax

\section{Bangladesh}

\section{Mir. Muhammad Hassan}

Director

Bangladesh Forest Research Institute

P.O. Box 273, Chittagong - 4000

880-31-210901 fax

\section{Bhutan}

\section{M.R. Moktan}

Department of Forestry

Ministry of Agriculture

Thimphu

975-22924 fax

\section{China, People's Republic of}

\section{Wang Huoran}

The Chinese Academy of Forestry

Wan Shou Shan

Beijing 10091

86-1-25823I7 fax

\section{Wang Hong}

The Research Institute of Forestry The Chinese Academy of Forestry Wan Shou Shan, Beijing 100091 86-1-25823I7 fax

\section{Costa Rica}

\section{Edgar Viquez}

Head of Research Department Maderas de Costa Rica Institute

Department of Agroforestry

CATIE, 7170 Turrialba

San Jose

506-231-1057 fax
India

D.N. Tewari

Director General

Indian Council of Forest Research and Education

P.O. New Forest

Dehra Dun 248006

91-135 23258 fax

V.K. Bahuguna

Conservator of Forests

Office of the Conservator of Forests

Northern Circle, Kumarghat

Tripura (N) - 799264

91-381-224013 fax

\section{Indonesia}

\section{Emmy Hafild}

The Indonesia Forum for Environment (WAHLI)

Jl. Mampang Prapatan XV No. 41

Jakarta 12790

62-21-799-1673 fax

\section{Sudijono}

Manager of Logging Operations

P.T. International Timber Corp. Indonesia (ITCI)

Jl. Harsono RM No. 54

Ragunan Pasar Minggu

Jakarta 12550

62-2-17801017 fax

\section{Malaysia}

\section{Wong Wing Chong}

Head, Research Planning \& Evaluation Unit

Forest Research Institute

Kepong, Selangor, Kuala Lumpur

60-3-6342825, 60-3-6367753 fax

\section{Cyril Pinso}

Innoprise Corporation SDN. BHD.

P.O. Box 11622,

88817 Kota Kinabalu

60-88-233672 fax

\section{Gurmit Singh}

Centre for Environment, Technology

\& Development, Malaysia (CETDEM)

P.O. Box 382, 46740 Petaling Jaya

60-3-7754039 fax 
Nepal

Rajendra B. Joshi

Act. Executive Director

Ministry of Forests and Soil Conservation

Forest Research and Survey Centre

P.O. Box 3339, Babar Mahal

Kathmandu

977-1-220 159 fax

\section{The Netherlands}

Paul J. M. Hillegers

Head, Department of International Affairs Institute for Forestry and Nature Research Bosrandweg 20, P.O. Box 23

6700 AH Wageningen

31837024988 fax

New Zealand

S. Devine

Manager Public Good Research

Foundation for Research, Science \& Technology

P.O. Box 12-240

Wellington

64-4-499-2568 fax

\section{Pakistan}

\section{K.M. Siddiqui}

Director General

Pakistan Forest Institute

Peshawar

92-521-42457 fax

\section{Papua New Guinea}

David Skel ton

Divisional Manager

Reforestation Branch, National Forest Service

Papua New Guinea Forest Authority

P.O. Box 5055, Boroko

675-277930,675-254433 fax

\section{Philippines}

\section{M.L. Garcia}

Division Manager

Paper Industries Corporation of the Philippines Julia Vargas Avenue, Corner Garnet St. Ortigas Complex, Pasig, Metro Manila 63-3-5946 fax

\section{Sri Lanka}

\section{H.P.M. Gunasena}

Dean, Faculty of Agriculture

University of Peradeniya

Peradeniya

94-8-88041/32572 fax

\section{Taiwan}

\section{Hsu-Ho Chung}

Head, Division of Forest Management

Taiwan Forestry Research Institute

53 Nan-Hai Road, Taipei 107

886-2-375-4216 fax

\section{Thailand}

Suree Bhumibhamon

Faculty of Forestry

Kasetsart University

Bangkok 10903

66-2-5611041 fax

\section{Wanida Subansenee}

Director, Forest Products Research

\& Development Division

Royal Forest Department

Phaholyothin Road, Chatuchak

Bangkok 10900

66-2-5791537 fax

\section{U.S.A}

Mieke van der Wansem

Coordinator for Asia and the Pacific

Center for International Development \&

Environment

World Resources Institute (WRI)

1709 New York Avenue, N.W.

Washington, D.C. 20006

1-202-638-0036 fax

\section{Vietnam}

Hoang Hoe

President

The Vietnam Forestry Association

$123 \mathrm{Lu}$ Duc Street

Hanoi

84-4-211227 fax 


\section{Nguyen Huy Dzung}

Forest Resources \& Environment Centre (FREC)

Forest Inventory and Planning Institute (FIPI)

Thanhtri, Hanoi

84-4-612881 fax

\section{Zimbabwe}

\section{Yemi Katerere}

General Manager, Forestry Commission

No. 1 Orange Grove Drive

P.O. Box HG 139

Highlands, Harare

263-4-497066 fax

\section{Asian Development Bank}

B.N.Ganguli

Senior Forestry Specialist

Asian Development Bank (ADB)

P.0. Box 789

Manila 1099

Philippines

63-2-7417961, 63-2-6816 fax

\section{Asean Forest Tree Seed Centre}

James F. Coles

Canadian Project Manager

ASEAN Forest Tree Seed Centre Project

Muak Lek, Saraburi 18180

Thailand

66-36-341 859 fax

\section{Asia-Pacific Agroforestry N etw ork (APAN)}

\section{Chun K. Lai}

Regional Coordinator

Asia-Pacific Agroforestry Network

(GCP/RAS/ 133/JPN)

P.O. Box 481 Bogor 16004

Indonesia

62-251-315222 fax

\section{CAB International}

\author{
Arun Kashyap \\ Senior Project Officer \\ CAB International \\ P.O. Box 11872 \\ 50760 Kuala Lumpur \\ Malaysia \\ 60-3-2551888 fax
}

\section{CARE International}

Douglas R. Henderson

Regional Technical Advisor

Agriculture and Natural Resources

CARE International

134 Havelock Road

Colombo 5

Sri Lanka

94-1-587572 fax

\section{CIFOR}

Thomas Enters

Research Fellow

Center for International Forestry Research

P.O. Box 6596 JKPWB

Jakarta 10065

Indonesia

62-251-326433 fax

\section{FAO/RAPA}

\section{A.Z.M. Obaidullah Khan}

Assistant Director-General and Regional

Representative for Asia and the Pacific

FAO Regional Office for Asia and the Pacific

Phra Atit Road, Bangkok 10200

Thailand

66-2-2800445 fax

\section{Jon Anderson}

Forestry Officer (Extension)

Forestry Department

FAO Headquarters

Rome, Italy

39-6-52253152 fax

\section{Patrick Durst}

Regional Forestry Officer

FAO Regional Office for Asia and the Pacific

Phra Atit Road, Bangkok 10200

Thailand

66-2-2800445 fax

\section{Kashio}

Regional Forest Resources Officer

FAO Regional Office for Asia and the Pacific

Phra Atit Road, Bangkok 10200

Thailand

66-2-2800445 fax 


\section{Berenice Muraille}

Forestry Consultant, Forestry Section

FAO Regional Office for Asia and the Pacific

Phra Atit Road, Bangkok 10200

Thailand

66-2-2800445 fax

Michael Jensen

Associate Professional Officer

Forestry Section

FAO Regional Office for Asia and the Pacific

Phra Atit Road, Bangkok 10200

Thailand

66-2-2800445 fax

\section{S.K. Bhargava}

Chief Technical Advisor

GCP/RAS/137/JPN

FAO Regional Office for Asia and the Pacific

Phra Atit Road, Bangkok 10200

Thailand

66-2-2800445 fax

\section{Lars Wollesen}

Forestry Expert

GCP/RAS/137/JPN

FAO Regional Office for Asia and the Pacific

Phra Atit Road, Bangkok 10200

Thailand

66-2-2800445 fax

\section{Willem Hulscher}

Chief Technical Advisor

GCP/RAS/ I 54/NET

FAO Regional Office for Asia and the Pacific

Phra Atit Road, Bangkok 10200

Thailand

66-2-2800445 fax

\section{Harry Oosterveen}

Associate Professional Officer

GCP/RAS/154/NET

FAO Regional Office for Asia and the Pacific

Phra Atit Road, Bangkok 10200

Thailand

66-2-2800445 fax

\section{Conrado Hereula}

Consultant

GCP/RAS/154/NET

FAO Regional Office for Asia and the Pacific

Phra Atit Road, Bangkok 10200

Thailand

66-2-2800445 fax

\section{Auke Koopmans}

Consultant

GCP/RAS/154/NET

FAO Regional Office for Asia and the Pacific

Phra Atit Road, Bangkok 10200

Thailand

66-2-2800445 fax

\section{C.T.S. Nair}

Senior Programme Advisor GCP/RAS/134/ASB, FORSPA

FAO Regional Office for Asia and the Pacific Phra Atit Road, Bangkok 10200

Thailand

66-2-2804565, 66-2-2800445 fax

\section{Anders Jensen}

Associate Professional Officer

GCP/RAS/134/ASB, FORSPA

FAO Regional Office for Asia and the Pacific Phra Atit Road, Bangkok 10200

Thailand

66-2-2800445 fax

\section{IUFRO}

\section{Brian Payne}

Coordinator, IUFRO/SPDC

International Union of Forestry

Research Organizations

c/o Federal Forest Research Station

Seckendorff-Gudent-Weg 8

A-1131 Vienna

Austria

43-1 8779355 fax

\section{M.N. Salleh}

President

International Union of Forestry Research

Organization (IUFRO)

Forest Research Institute Malaysia (FRIM)

Kepong, Selangor, Kuala Lumpur

Malaysia

60-3-6342825, 60-3-6367753 fax 